\title{
THE FOUR PILLARS OF AN AUTOMATED NOTIFICATION AND CONTROLLING INFORMATION SYSTEM FOR CURRICULUM ADVISEMENT
}

\author{
Xue Bai, Virginia State University, xbai@vsu.edu \\ Ahmet Ozkul, University of New Haven,aozkul@newhaven.edu \\ Fidelis Ikem, Albany State University, fidelis.ikem@asurams.edu
}

\begin{abstract}
Curriculum advising is a central and important activity in the process of academic advising. It plays a critical role in helping students choose a program of study that will serve them in the development of their total potential. The success of academic advising can be highly dependent on the monitoring and controlling the curriculum progress. This paper presents four pillars of an automated notification and controlling system to help students and advisors effectively monitor and control curriculum progress.
\end{abstract}

Keywords: Information Systems, Curriculum Advisement, Automated Systems

\section{INTRODUCTION}

Academic advising is integral to fulfilling the teaching and learning mission of higher education. As a central and important activity in the process of higher education, it plays an important role in achieving a successful academic career. In many colleges, curriculum advising occurs at least once each term for every student in the college. Few student personnel functions occur as often or affect so many students as curriculum advising. Through curriculum advisement, students are informed about their degree requirements, curriculum progress is reviewed, future course plans are updated, and issues (if any) are identified. They are then referred to the appropriate sources for information or corrective actions. For example, if a student experiences academic difficulty, such as failing to take courses required by their curriculum or not meeting the minimum GPA requirements for an academic program, relevant individuals such as the student, advisors, and administrators are notified via the curriculum advising process to enable them to take appropriate actions.

While there is general agreement concerning the importance of curriculum advising for the efficient functioning of the institution and the effective functioning of the student, there is little effort made to improve the efficiency and effectiveness of the curriculum advisement practice. Since 1988, many institutions have implemented the Banner suite for advising, registration, grading, and other functions. However, the nature of academic advising process has not changed for decades. On many campuses the current implementation of curriculum advisement or academic advising is still limited to course registration, and most of the work is performed manually by students, advisors, or both. In the following sections, we discuss the current implementation of the curriculum advisement process and its limitations, and then present an automated monitoring and controlling system that consists of four pillars for advancing curriculum advisement.

\section{Current Implementation of Curriculum Advising Process}

At most regional level universities, the process of registering all students is largely concentrated into a very short period of time. In the school of business at a median size university with enrollment of about 1000 students, student registration takes place twice every academic year, in March and October. The registration in March is for the following fall semester and the one in October is for the following spring semester and summer school. Registration for each semester lasts about two weeks. In addition to the regular registration period, students are given chances to register for courses during the first week after classes start if seats are available or to adjust their earlier registration. The school of business offers four undergraduate majors. Students are required to take 120 credits hours over a four year period to graduate. The curriculum for each major is broken down into two phases: the first 60 credit hour, which consists of freshman and sophomore years, is called the pre-business phase; while the remaining 60 credit 


\section{Issues in Information Systems}

Volume 13, Issue 2, pp. 72-81, 2012

hours, consisting of junior and senior years, is called the business phase. All majors have the same curriculums for the pre-business phase. Upon completion of the pre-business phase with minimum GPA requirement of 2.50, students are permitted to the business phase; otherwise they are advised to repeat some courses with low grade to improve their GPAs. For the business phase, curriculums are individually designed for each major. Each major's curriculum consists of two parts: courses required for the major and elective courses. In order to receive degree in a specific major, students have to take all required courses for that major. Students can take any courses from the elective course list.

In order to facilitate the registration process and ensure that students take the right courses at the right time to complete their program of study, all students are assigned advisors and they have to meet with their advisors to decide what courses they need to take for each semester. An advisement center in the school of business with three staff helps pre-business phase students' registration. Each department handles its business phase students' registration. Furthermore, as part of curriculum advising, advisors conduct a special review of the records of students who have completed 90 credit hours of course work. One purpose of this 90 -hour review is to ensure that a student has completed 90 credit hours of course work listed in their major curriculum. The data needed for the advisement and curriculum review are either from student's folder or directly retrieved from the Banner system.

The advisement center staff advise and assist pre-business phase students with their registration. Upon successfully completing pre-business, students are directed to their department for registration advisement. When a new freshman enters the school of business program, a folder will be created and maintained in the advisement center for at least two years. The folder is used to track all registration documents through students' academic career in the school. To prepare registration documents for students, advisors need to look into individual student folders to view registration records including the courses taken in the past and the courses the student is currently taking, and then use the curriculum as guidance to help students decide which courses towards their major they need to take in the following semester. The proposed courses for the following semester are recorded in the Registration Form and a copy of the form is placed in the student folder. When registration begins, all pre-business phase students are scheduled to meet with advisors in the advisement center. During this meeting, advisors discuss the prepared registration form with students and then enter the courses into the Banner course registration system. The registration form is kept in the student folder. Students' folders will be transferred to the students' department when the students complete the pre-business phase. Each business phase student is assigned to a faculty member in their department. To register courses for the following semester, students must meet with their assigned advisors during the registration period and advisors will prepare registration forms. In a typical situation, faculty member spend at least 30 minutes with each student to prepare the registration form. Figure 1 shows the general process of the manual advising and registration process.

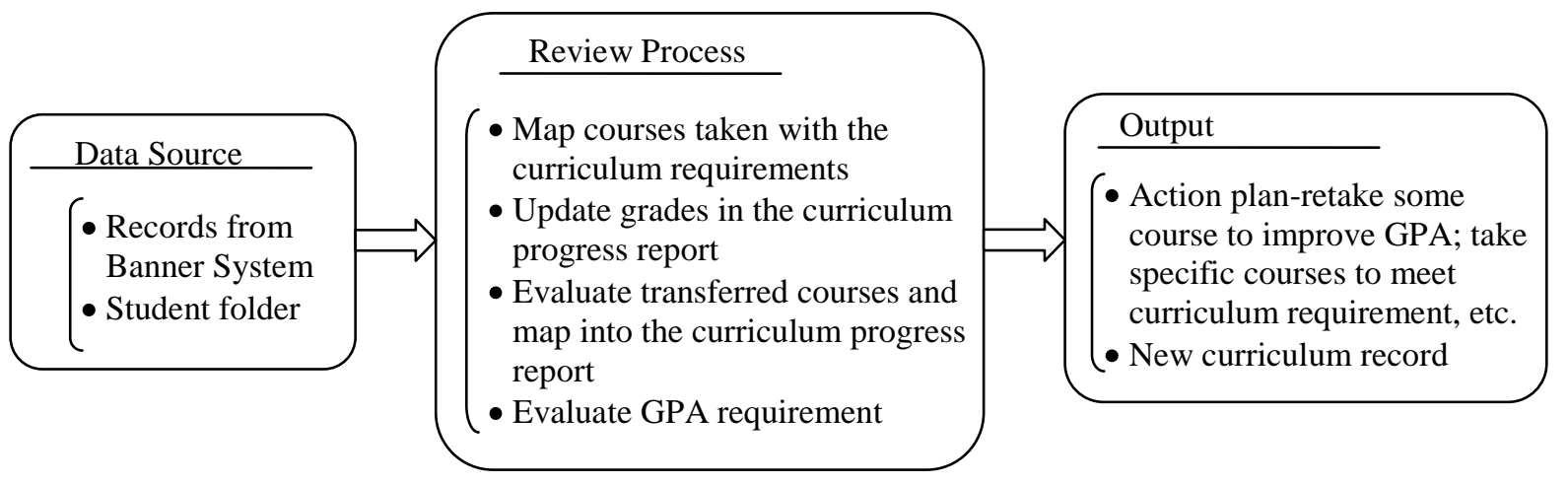

Figure 1: The process of manual advising and registration process 


\section{Issues in Information Systems}

Volume 13, Issue 2, pp. 72-81, 2012

\section{Deficiency of the Current Registration Process}

Advisors create a folder for each student to track student academic progress towards his/her major. A copy of the course registration form for each semester is placed in the student's folder. Others use these forms during the registration process. One registration form is supposed to be created for each semester. However, at our university, we randomly reviewed 50 folders of students who have graduated and found that none of them were complete. Registration forms for some semesters were missing, or there were two or more registration forms for a single semester. Many forms had inaccurate information about student curriculum progression history. For example, some forms failed to recognize that a student had dropped some classes in the middle of a semester or a student did not pass courses that must be retaken. Therefore, those forms cannot be used as a reliable source of support for the registration process. As a consequence, most advisors use the Banner system to access student academic records for registration purposes.

The Banner system maintains all students' records. Unfortunately, the system provides no connection with program curriculum. It simply is a repository database for students' course records. Essentially it maintains student transcripts. Therefore, it cannot be directly used to determine what courses a student needs to take. In most cases, to advise a student to register for courses, advisors print out the student course record from the Banner system. They then review all records, noting on the curriculum sheet courses completed and courses the student is currently enrolled in to determine what courses need to be taken. This is a time consuming process that is repeated over and over every semester and has been a source of complaints from both faculty and students.

Sometimes this process becomes more complex. For example, for some elective courses, advisors need to look at an elective course list to determine how to map those courses onto the curriculum sheet. It is even more challenging if a student has transferred courses. The Banner system simply lists a transferred course name and credit hours. It does not provide any information about substituted courses in the curriculum. When they encounter such situation, advisors must meet with the chairperson of the department offering the course to discuss how to map transferred courses to those listed in the program curriculum. In some cases, this process takes from a few hours to a few days to complete. This tedious process leads to mistakes in many students' records that cause significant problems in their attempt to graduate on time. For example, some students take some classes that they incorrectly think are required classes for the academic program. As a result, they may have to postpone graduation. Another common problem is student confusion about requirements for admission to the business phase. In order to be admitted to the business phase, students must complete the pre-business phase with a minimum GPA of 2.50. At the end of one semester, we checked 125 senior students from three institutions and found that 15 of them did not meet the minimum GPA requirements. When we talked to these students about the situation, they responded that they knew neither the minimum GPA requirements nor their GPAs for pre-business phase.

\section{Possible off-the-shelf solutions}

Many higher education institutions prefer off-the-shelf academic advising modules that comes along with a larger enterprise system, due to cost efficiencies and having to deal with only one single vendor. Despite the benefits, these systems may require significant changes in the existing advising rules and processes, or in the software package itself.

We reviewed some academic systems available commercially before deciding to develop a system in house. Being one of the most commonly used systems in the country, including our own, we first considered the Banner enterprise planning system by SunGard Higher Education Solutions [1]. Currently the entire academic package marketed by the company includes the following modules.

1) Academic Technology Services

2) Banner Student Retention Performance

3) Course Signals

4) DegreeWorks

5) Grants Services 


\section{Issues in Information Systems}

Volume 13, Issue 2, pp. 72-81, 2012

6) Online Learning Services

7) Student Success and Retention Planning Services

8) Epsilen Environment

These modules are usually purchased separately depending on the needs of institutions and customized according to the specific regulations and rules of the institution. School rules on prerequisites, graduation requirements, recommended course sequences, major core and electives courses, technology, critical thinking and other liberal art course requirements may vary extensively from one institution to another and make the customization process difficult and time consuming. Furthermore, some of the workflows and rules may not be adequately captured by the customization due to rigidity inherent in any off-the-shelf-solution. Even if the system is customized and ready to use, administration, faculty and student adaptation may be slow and even the system could be completely or partially rejected, leading to some of its capabilities left unused. For example, the DegreeWorks (or Curriculum, Advising, Program Planning - CAPP) module presents advisors up-to-date information on students, courses taken and progress made. However, as indicated previously, the current version installed in our institution lacks certain critical features (such as timely warnings of prerequisites or information on transfer credits), and considered too rigid due to poor customization (such as the Planner capability for future courses). Other systems we reviewed includes academic advisement module in PeopleSoft enterprise system [2], Degree Navigator of Decision Academic [3], and redLantern/DARS [4]. They provide excellent tools for traditional advising tasks but lack more advanced (such as intelligent scheduling) tools. Since we could not found an exact match satisfying needs of our students and faculty, we developed an automated system described in the following sections.

\section{AN AUTOMATED NOTIFICATION AND CONTROL SYSTEM}

Good advising is vital to the long-term success of an institution. An effective and efficient advising system can make a huge difference in the quality of the educational experience a university provides its students. In the past, the quality of academic advising depended largely on the advisor's experience and knowledge of curriculum requirements. As discussed before, the current academic advisement process is time consuming and error prone. To meet the ever increasing demands for an effective advising system, we designed a new integrated automated system to minimize the knowledge requirements for advising while providing all necessary information for advising. The system provides students, advisors and administrators with accurate and complete information about degree requirements including a complete curriculum progress report. The system is capable of identifying any discrepancy from curriculum requirements in a timely manner and automatically sends messages with recommendations on appropriate actions to be taken by appropriate individuals.

Regardless a manual or an automated academic advisement system, an effective advisement is not only to identify the discrepancies from the curriculum requirements but also to ensure appropriate action plans to be generated and implemented. Therefore, a successful advising system should be a closed loop control system which provides a mechanism to ensure the output is evaluated and used to improve the performance. As shown in figure 2, in a closed loop control system, information about performance is measured and that information is used to correct how the system performs.

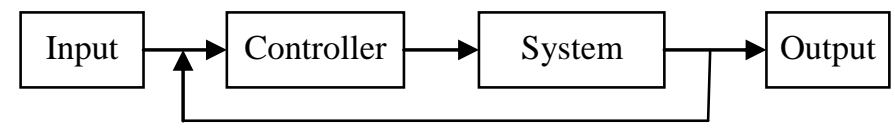

Figure 2: Close loop control system

In a manual advising system, even though a particular action plan could be created after a long and cumbersome advising process, there is no build-in feedback loops to monitor and enforce the action plan to be implemented, the action plan turns to be in vain. The automated notification and control system applies the basic principles underlying the analysis and design of control systems. Control System is a science that looks into the control of complex systems for the purpose to obtain a desired output with a desired performance given a specified input [5]. Closed loop control systems rely on the feedback loop which provides the control system information of the system's current state in an effort to update the control system. Control system theories have been applied to many 


\section{Issues in Information Systems}

Volume 13, Issue 2, pp. 72-81, 2012

disciplines such as robotics [6], automotive [7], and freeway vehicle traffic [8]. The controller acts on the error signal and uses that information to produce the signal that actually affects the system we are trying to control. Therefore, the controller has to provide "enough power" to drive the system. To "control" an object means to influence its behavior so as to achieve a desired goal. Similarly, for the automated notification and controlling advising system, the successful academic advisement report and student's academic success are the outputs and inputs are the student's records. And the controller of the system is implemented through the messaging and monitoring and controlling mechanism. As described in the following sections, the system consists of four pillars: Data Sources, Dada Analysis, Messaging, and Monitoring and Controlling.

\section{Four Pillars of the Automated Advising System}

The system consists of four sub-systems to ensure students, advisers and administrators receive timely, accurate, and professional assistance in planning and completing their academic career in a program. Figure 3 illustrates the four pillars of the system.

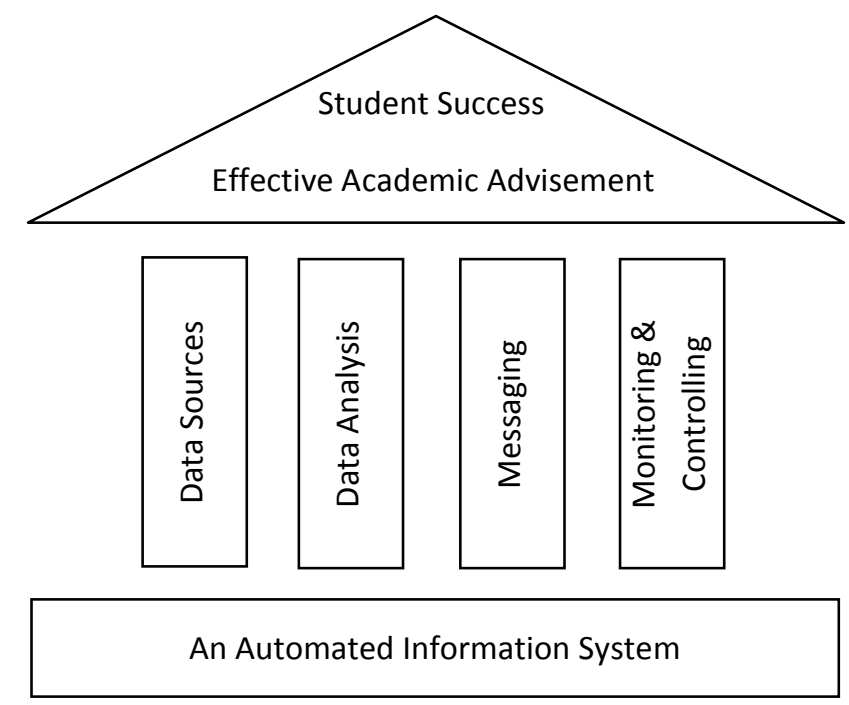

Figure 3: Four Pillars of the Automated Advisement System

The system is highly integrated because it shares a common database. The common database is shared by everyone who uses the system, which makes it easy to maintain records on students. It provides the features and processing capabilities needed for advising (curriculum progress status, registration, courses currently in progress, courses to be taken, etc.). Because of the common database, multiple departments use the same information provided by the system. The system has a variety of tools that allow searching for a student and automatically retrieving associated information. It also has sophisticated security measures to make sure that only authorized individuals have access to specific data. The system not only generates action plans but also provides systematic channels to enforce the action plan to be carried out. This new information system provides effective advisement practices with its four functional components: Data Sources, Data Analysis, Messaging, and Monitoring \& Controlling.

\section{Data Sources}

A database is designed for the system. As illustrated in Figure 4, the data sources include curriculum, elective courses, curriculum progress records, rules and regulations, and records of fulfilled action plans.

Each sub-component serves as an input for data analysis. For example, the rules and regulations are associated with the curriculum requirements of each program and degree, academic transfer, and GPA requirements. Curriculum Progress Records show the current status of students towards their proposed degree program. The report also 


\section{Issues in Information Systems}

Volume 13, Issue 2, pp. 72-81, 2012

highlights the courses that are completed successfully, courses that are in process, courses to be retaken, and courses to be scheduled for following semester, and courses required by curriculum.

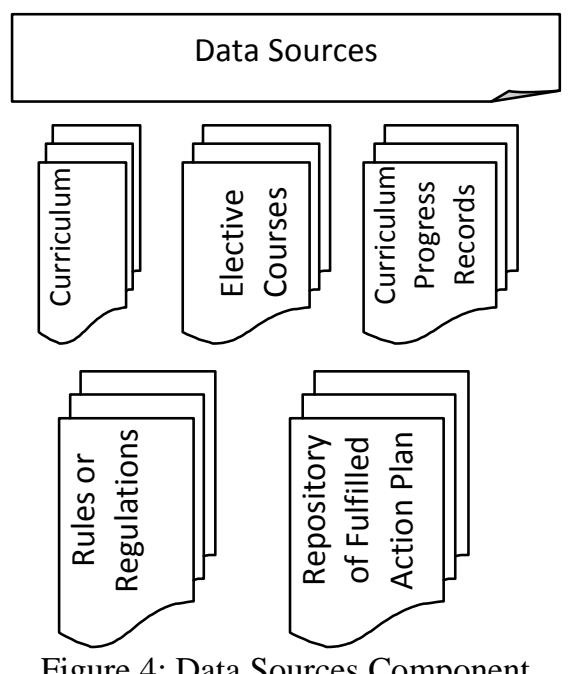

Figure 4: Data Sources Component

\section{Data Analysis}

This module, as illustrated in Figure 5, implements the curriculum rules and regulations associated with the each program. It generates curriculum progress status for each student and identifies any issues or risks the student may have. The system is capable of providing a specific action plan to deal with those problems. In a traditional advisement system, it took a huge amount of effort for advisors to identify a problem and propose an appropriate action plan. With the automated system, this task is carried over automatically. For example, if the system detects that some courses the student registered for the next semester are not part of his/her curriculum requirements, it will generate warning messages and action plans for the situation, and the warning messages and action plant will be sent to both advisors and the student through the messaging system.

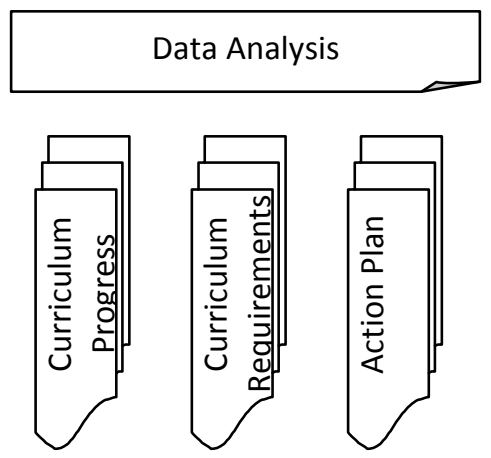

Figure 5: Data Analysis Component

Some of the tasks performed automatically in this module include 90-hour review report for those students who completed 90 credit hours and Clearance Form for Graduation. This module also generates a list of students who have been admitted into business phase without meeting the minimum GPA requirements. Administrators use this information to take immediate action to correct the potential problems caused by other systems. In addition to the action plan, the system also sends warning messages to relevant individuals. The results of the data analysis are used to generate action plans. 


\section{Issues in Information Systems}

Volume 13, Issue 2, pp. 72-81, 2012

\section{Messaging}

Social networking sites are a type of virtual community that has grown tremendously in popularity over the past few years. For example, as of May 2012, Facebook has over 900 million active users, more than half of them using Facebook on a mobile device [9]. The web traffic data for Facebook, a social networking site oriented towards college students, shows 15 million unique US visitors a month (QuantCast, 2007a). Social networking sites have affected the social life and activity of people in various ways. With its availability on many mobile devices, they allow users to continuously stay in touch with friends, relatives and other acquaintances wherever they are in the world, as long as there is access to the Internet. It can also unite people with common interests and/or beliefs through groups and other pages, and has been known to reunite lost family members and friends because of the widespread reach of its network. In fact, most of college students have instant access to the Twitter and Facebook sites. By integrating the social networking applications with the messaging system as shown in Figure 6, relevant individuals will be immediately notified with the action plans through the social networking sites. So, for each action plan generated by the system, a corresponding message will be automatically sent to appropriate individuals via email or other social networking sites such as Twitter and Facebook. The system also displays the alert message upon signing into the system and suggests detailed action plans to deal with issues identified.

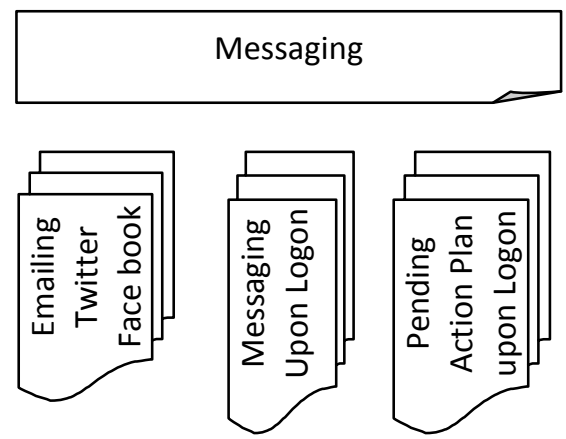

Figure 6: Messaging Component

All of the action plans and corresponding messages are prioritized. The prioritized messages are monitored and controlled through the fourth pillar of the system: Monitoring and Controlling component.

\section{Monitoring and Controlling}

This module in Figure 7 provides a mechanism for advisers and administrators to ensure all actions plans to be implemented successfully and in a timely manner. This module comprises monitoring pending action plan, generating new action plan as needed, and sending new messages.

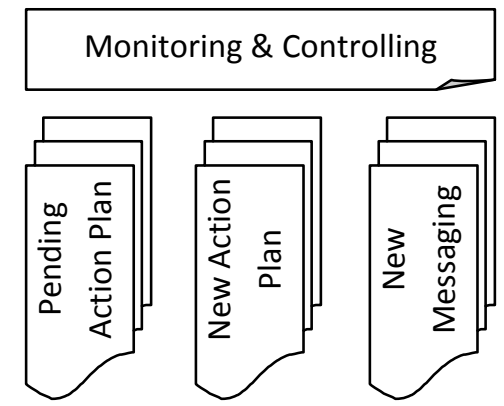

Figure 7: Monitoring \& Controlling 


\section{Issues in Information Systems}

Volume 13, Issue 2, pp. 72-81, 2012

For example, all action plans and messages are time-stamped. This means that all action plans must be carried out within a specified time window. When generating a message, the system put two time stamps to the message: the receivers must acknowledge within the time-stamped deadline that they have received the message; and the action plan must be implemented within the certain period of time. Otherwise, the system will generate a new action plan and messages for supervisors.

\section{SUMMARY}

The system provides a single resource for all interested parties: students, advisors, and administrators. It is easily accessible to students, advisors, and administrators. The system records all courses students have taken and maps those courses to curriculum progress report. In addition to providing accurate curriculum reports for students, advisors, and administrators, it can also identify any deviations from curriculum requirements. Also, since students are authorized to access the system, they are well informed by their curriculum progress status and they know what is required to be successful.

In some institutions, academic advising is cumbersome and ineffective for both students and faculty. It requires advisors to have extensive experience and knowledge about curriculum requirements. With the automated information system, even new faculty members without any experiences can conduct academic advising effectively. With the integration and automation of registration process, curriculum progress reporting, and academic status monitoring and controlling, the system provides access to accurate and up-to-date curriculum progress status. It also notifies users of any actions they need to take. With the implementation of the four information system pillars, the automated advising system provides an effective mechanism to monitor curriculum progress and hence to advance academic advising function of academic units.

\section{REFERENCES}

1. SunGard Higher Education Solutions, http://www.sungardhe.com/solutions/, Accessed on April 20, 2012.

2. PeopleSoft Enterprise Academic Advising Solutions, http://www.oracle.com/us/products/applications/peoplesoft-enterprise/052357.html, Accessed on April 24, 2012.

3. Degree Navigator module, Decision Academic Solutions, http://www.decisionacademic.com/products/degree-navigator, Accessed on April 24, 2012.

4. u.direct, u.select, u.achieve, Redlantern Academic Solutions, http://www.redlanternu.com/, Accessed on April 24,2012

5. Nise, N. S. (2010). Control Systems Engineering (6th ed.). Hoboken, NJ: John Wiley.

6. Sharkawy, A. B., \& Salman, S. A. (2011). An adaptive fuzzy sliding mode control scheme for robotic systems. Intelligent Control and Automation, 2, 299-309.

7. Aly, A., Zeidan, E., Hamed, A., \& Salem, F. (2011). An antilock-braking systems (ABS) control: A technical review. Intelligent Control and Automation, 2, 186-195.

8. Coifman, B., \& Kim, S. (2009). Speed estimation and length based vehicle classification from freeway single loop detectors. Transportation Research Part-C, 17, 349-364.

9. Sengupta, Somini (May 14, 2012). "Facebook's Prospects May Rest on Trove of Data". The New York Times. Retrieved May 15, 2012. 


\section{Issues in Information Systems}

Volume 13, Issue 2, pp. 72-81, 2012

\section{Appendix A: The Database for the System}

A database is designed for the system. The information required includes a description of users including faculty members, administrator, and students, courses required by a program curriculum, lists of elective courses for each program, advisors assigned to students, and course history that students took or are currently taking. User tables (Students, Faculty, and Admin) are to be described by such data as: name, account IDs , password, and other personnel information such as phone address, etc.. Curriculum table stores course requirements for each program or major; Elective table lists all selective courses. Advisor table records students' ID and advisors' ID for each semester. The Course History table stores all courses taken or being currently taken by students. The tables are their relationships are summarized in Figure 7.

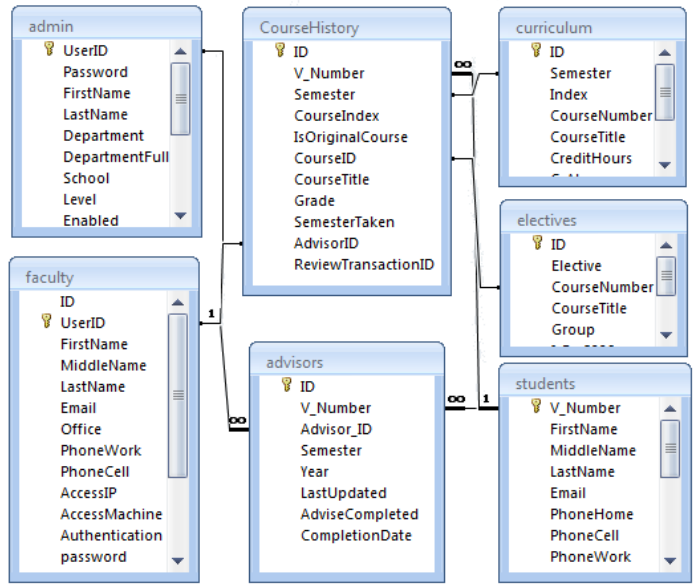

Figure 7: Tables and Their Relationships

\section{Appendix B: The Website Map of the System}

The system web site map, as shown below, provides a list of web pages on the web site. The hierarchical structure of the sitemap shows pages accessible to different users. The sitemap can be used as a planning tool for web design.

The Website Map:

- Authentication (User Login)

- Action Plan and Repository

o Messaging Center

- Emailing

- Twitter

- Facebook

Controlling

- On-screen messages upon logon

- Student Access

- Curriculum Sheet for his/her major

- Elective Course List

- Curriculum Progress Report

- Advisor Information 


\section{Issues in Information Systems}

Volume 13, Issue 2, pp. 72-81, 2012

- Profile

- Advisor Access

- Curriculum Sheets for all Programs

- Elective Course List for all Programs

- Advisee List

- Student Curriculum Progress Report

- Update Curriculum Status

- Profile

- Admin Access

- Faculty List

- Faculty Member Advisee List

- Advisement Status

- Student List

- Student Curriculum Progress Report

- Update Curriculum Status

- Account Management

- Student Management

- Faculty Management

- 60-hour and GPA Status Check

- 90-hour Review

- Clearance for Graduation

- Profile 